\title{
Complexos enzimáticos sobre a energia metabolizável e digestibilidade dos nutrientes do milheto para frangos de corte
}

\author{
[Enzyme complexes on metabolizable energy and nutrient digestibility of millet for broiler chickens] \\ F.A.S. Moura ${ }^{1}$, L.R.B. Dourado ${ }^{2}$, L.A. Farias ${ }^{2}$, J.B. Lopes $^{3}$, \\ S.B.P. Lima ${ }^{2}$, M.L. Fernandes ${ }^{4}$ \\ ${ }^{1}$ Aluno de pós-graduação - Universidade Federal do Piauí - Teresina, PI \\ ${ }^{2}$ Universidade Federal do Piauí - Bom Jesus, PI \\ ${ }^{3}$ Universidade Federal do Piauí - Teresina, PI \\ ${ }^{4}$ Aluna de pós-graduação - Universidade Estadual de Santa Cruz- Ilhéus, BA
}

F.A.S. Moura https://orcid.org/0000-0003-1569-719X L.R.B. Dourado https://orcid.org/0000-0001-7141-6677 L.A. Farias

(1) https://orci J.B. Lopes
https://orcid.org/0000-0002-0133-4366 https://orcid

https://orcid.org/0000-0002-5664-3326 M.L. Fernandes https://orcid.org/0000-0001-7618-0798

\begin{abstract}
RESUMO
Objetivou-se avaliar o efeito de complexos enzimáticos sobre a energia metabolizável e o coeficiente de digestibilidade de nutrientes do milheto para frangos de corte. Quinhentos e setenta e seis frangos machos foram distribuídos em 36 gaiolas, com três tratamentos: T1 - composição de milheto sem complexo enzimático; T2 - composição de milheto com complexo enzimático (CES) e T3 - composição de milheto com complexo enzimático (CEV). Os tratamentos foram definidos com base em seis dietas (três dietas referências e três dietas testes). As dietas testes foram obtidas pela substituição de $40 \%$ da dieta referência por milheto inteiro, e a adição de enzimas consistiu de dois complexos enzimáticos: CES, constituído pelas enzimas fitase, protease, xilanase, $\beta$-glucanase, celulase, amilase e pectinase; e CEV. constituído pelas enzimas protease, celulase e amilase. Na fase de 11 a 20 dias, a suplementação com o CEV reduziu os valores de EMA, EMAn e CDPB. A suplementação com CES melhorou o CDPB, e não houve efeito significativo para CDMS e CDEB. $\mathrm{Na}$ fase de 21 a 30 dias, houve menor aproveitamento da energia e dos nutrientes com as suplementações CES e CEV. Na fase de 31 a 40 dias, as suplementações reduziram os valores de EMA, EMAn, e o complexo CEV foi efetivo em aumentar o valor de CDPB. A inclusão dos complexos enzimáticos CES (fitase, protease, xilanase, $\beta$-glucanase, celulase, amilase e pectinase) e CEV (protease, celulase e amilase) não favoreceu a utilização da energia do milheto, no entanto melhorou o coeficiente de digestibilidade da proteína do milheto nos períodos de 11 a 20 e de 31 a 40 dias de idade.
\end{abstract}

Palavras-chave: alimento alternativo, dietas, enzimas, protease, xilanase

\begin{abstract}
The objective of this study was to evaluate the effect of enzymatic complexes on metabolizable energy and nutrient digestibility coefficient of millet for broilers chickens. 576 male chickens, were distributed in 36 cages with three treatments: T1 - millet composition without enzymatic complex; T2 - millet composition with enzymatic complex (ECS); and T3 - millet composition with enzymatic complex (ECV). The treatments were defined from six diets ( 3 reference diets and 3 test diets). The test diets were obtained from the substitution of $40 \%$ for reference diet by whole millet, and the enzyme addition consisted of two enzymatic complex, ECS constituted by phytase, protease, xylanase, $\beta$-glucanase, cellulase, amylase and pectinase enzymes, and ECV constituted by protease, cellulase and amylase enzymes. In the 11 to 20 days phase, a supplementation with the $E C V$ reduced the $A M E$, AMEn and CDPB values, a ECS supplementation improved the CDPB, and there was no significant effect for CDMS and CDEB. In the 21 to 30 days phase, there were less profit of the energy and nutrients with ECS and ECV supplements. In the 31 to 40 days phase as supplements reduced the values of $A M E$, AMEn, and the ECV complex was effective in increasing the value of CDPB. The inclusion of ECS enzymatic complexes, (phytase, protease, xylanase, $\beta$-glucanase, cellulase, amylase and pectinase) and ECV (protease, cellulase and amylase), did not favor millet's energy utilization, however, favored the millet's protein digestibility coefficient on 11 to 20 and 31 to 40 periods.
\end{abstract}

Keywords: alternative food, diets, enzymes, protease, xylanase

Recebido em 8 de maio de 2017

Aceito em 25 de maio de 2018

E-mail: netinhazoo@hotmail.com 


\section{INTRODUÇÃO}

$\mathrm{Na}$ produção avícola, busca-se a redução dos custos de produção com a utilização de ingredientes que possam compor as dietas e que atendam as demandas nutricionais dos animais, no entanto muitos ingredientes possuem fatores que impedem a utilização dos nutrientes, sendo necessária a aplicação de estratégias nutricionais para tornar possível a expressão do máximo desempenho produtivo.

O milho é o ingrediente mais utilizado nas formulações de rações para frangos de corte, mas outras fontes são empregadas em sua substituição. As principais razões para essa substituição são o fato de esse ingrediente sofrer oscilações de preço ao longo do ano, resultando na elevação dos custos de produção, e a possibilidade de utilização de ingredientes alternativos, como o milheto.

Em relação ao milho, o milheto apresenta maior teor de proteína, maior concentração de aminoácidos, como a lisina, metionina e treonina, com valor de energia bruta semelhante (Basto et al., 2005; Gomes et al., 2008; Rostagno et al., 2011).

A energia metabolizável do milheto para frangos de corte é inferior à do milho, mas algumas estratégias podem ser empregadas para melhorar os valores de energia e a disponibilidade dos nutrientes para esses animais, entre as quais a inclusão de enzimas exógenas que atuam na degradação da fibra dos alimentos, como exemplo, as xilanases, ß-glucanases, pectinases, celulases, ou para complementar as enzimas produzidas em quantidades insuficientes pelo próprio animal, como as amilases, proteases e lipases.

Apesar de o milheto não apresentar fatores antinutricionais, este contém uma fração fibrosa (12,5\%) (Rostagno et al., 2011), a qual pode ser degradada por enzimas exógenas que não são produzidas por animais não ruminantes, resultando em melhor resposta sobre a digestibilidade dos nutrientes.

O uso de enzimas em dietas para frangos de corte é recente e essa tecnologia tem evoluído bastante com o surgimento de novos produtos e melhor entendimento da relação entre a atividade enzimática e o substrato. As enzimas apresentam especificidade para cada nutriente e atuam na degradação da parede celular dos vegetais, como as celulases, ß-glucanases e xilanases (Brito et al., 2008), o que permite o acesso dos substratos contidos no conteúdo celular para melhor aproveitamento dos nutrientes (Oliveira et al., 2007), além de destruir os fatores antinutricionais presentes em alguns alimentos e potencializar a ação de enzimas endógenas, resultando em melhor desempenho produtivo. Entretanto, a maioria das recomendações se baseiam na matriz da enzima em dietas com milho e soja, sendo imprescindível, para uma formulação de precisão, o ajuste da matriz da enzima para cada tipo de ingrediente.

Diante do exposto, objetivou-se avaliar o efeito de complexos enzimáticos sobre a energia metabolizável e o coeficiente de digestibilidade de nutrientes do milheto para frangos de corte em diferentes fases de criação.

\section{MATERIAL E MÉTODOS}

O experimento foi aprovado pelo Comitê de Conduta Ética no Uso de Animais em Experimentação da Universidade Federal do Piauí, Campus Bom Jesus, PI, sob protocolo $n^{\circ}$. 087/2012.

O experimento foi conduzido em galpão convencional de frangos de corte do Colégio Técnico de Bom Jesus, PI, e as análises químicas, no Laboratório de Nutrição Animal do Departamento de Zootecnia da Unesp, em Jaboticabal, e da UFPI, em Teresina.

Foram realizados três ensaios de digestibilidade com frangos de corte, nas fases de 11 a 20, 21 a 30 e 31 a 40 dias de idade, com pesos médios iniciais de 221,3g, 793,0g e 1463,6g respectivamente, utilizando-se o método tradicional de coleta total de excretas descrito por Sakomura e Rostagno (2007).

Para definição dos três tratamentos, foram utilizadas seis dietas experimentais (Tab. 1), com seis repetições e seis aves por unidade experimental (no primeiro ensaio: 11 a 20 dias) e cinco aves por unidade experimental (no segundo: 21 a 30 dias e no terceiro ensaio: 31 a 40 dias), totalizando 576 frangos de corte, 
machos, da linhagem Coob 500, adquiridos com um dia de idade.

Tabela 1. Dietas experimentais ${ }^{1}$

\begin{tabular}{ll} 
D1 & \multicolumn{1}{c}{$100 \%$ dieta referência } \\
\hline D2 & $100 \%$ dieta referência + CES \\
D3 & $100 \%$ dieta referência + CEV \\
D4 & $\begin{array}{l}60 \% \text { dieta referência }+40 \% \text { de milheto } \\
\text { D5 }\end{array} \quad \begin{array}{l}60 \% \text { dieta referência }+40 \% \text { de milheto } \\
+ \text { CES }\end{array}$ \\
D6 & $\begin{array}{l}60 \% \text { dieta referência }+40 \% \text { de milheto } \\
+\mathrm{CEV}\end{array}$
\end{tabular}

${ }^{1}$ As dietas experimentais não constituem tratamentos; foram necessárias para a definição dos tratamentos e para os cálculos de digestibilidade.

O delineamento experimental utilizado foi $\mathrm{o}$ inteiramente ao acaso, com três tratamentos: milheto sem complexo enzimático, milheto + complexo enzimático S (CES), milheto + complexo enzimático $\mathrm{V}(\mathrm{CEV})$. As dietas foram constituídas de uma dieta referência (D1), formulada à base de milho, farelo de soja e suplementações com minerais, vitaminas e aminoácidos sintéticos, segundo as recomendações de Rostagno et al. (2011) (Tab. 2), e outra dieta teste (D4) foi obtida pela substituição de $40 \%$ da dieta referência por milheto inteiro.

À dieta referência e à dieta teste foram adicionados os complexos enzimáticos na proporção de $150 \mathrm{~g} /$ ton, os quais continham as enzimas fitase, protease, xilanase, $\beta$-glucanase, celulase, amilase e pectinase (CES), e as enzimas protease, celulase e amilase (CEV), formando as demais dietas experimentais D2, D3, D5 e D6 (Tab. 1).

Tabela 2. Composição das dietas referências

\begin{tabular}{|c|c|c|c|}
\hline Ingredientes \% & 11 a 20 dias & 21 a 30 dias & 31 a 40 dias \\
\hline Milho grão & 62,942 & 65,372 & 68,505 \\
\hline Farelo de soja & 32,158 & 29,676 & 26,244 \\
\hline Óleo de soja & 0,933 & 1,466 & 1,666 \\
\hline Fosfato bicálcico & 1,491 & 1,239 & 1,470 \\
\hline Calcário calcítico & 1,027 & 0,916 & 0,789 \\
\hline Dl-metionina & 0,313 & 0,266 & 0,241 \\
\hline L-lisina & 0,247 & 0,199 & 0,235 \\
\hline Sal comum & 0,239 & 0,222 & 0,201 \\
\hline Supl. min. vit. ${ }^{1}$ & 0,400 & 0,400 & 0,400 \\
\hline Inerte & 0,500 & 0,500 & 0,500 \\
\hline \multicolumn{4}{|c|}{ Composição nutricional e energética } \\
\hline Energ. met. aves (kcal/kg) & 2980 & 3050 & 3100 \\
\hline Proteína bruta $(\%)$ & 20,00 & 19,00 & 17,74 \\
\hline Lisina dig. aves $(\%)$ & 1,141 & 1,045 & 0,992 \\
\hline Met.+cist. dig. aves (\%) & 0,822 & 0,763 & 0,714 \\
\hline Ácido linoleico (\%) & 1,921 & 2,239 & 2,383 \\
\hline Fósforo disponível (\%) & 0,384 & 0,335 & 0,374 \\
\hline Cálcio (\%) & 0,860 & 0,750 & 0,751 \\
\hline Sódio (\%) & 0,210 & 0,200 & 0,191 \\
\hline Potássio (\%) & 0,526 & 0,507 & 0,481 \\
\hline \multicolumn{4}{|c|}{ 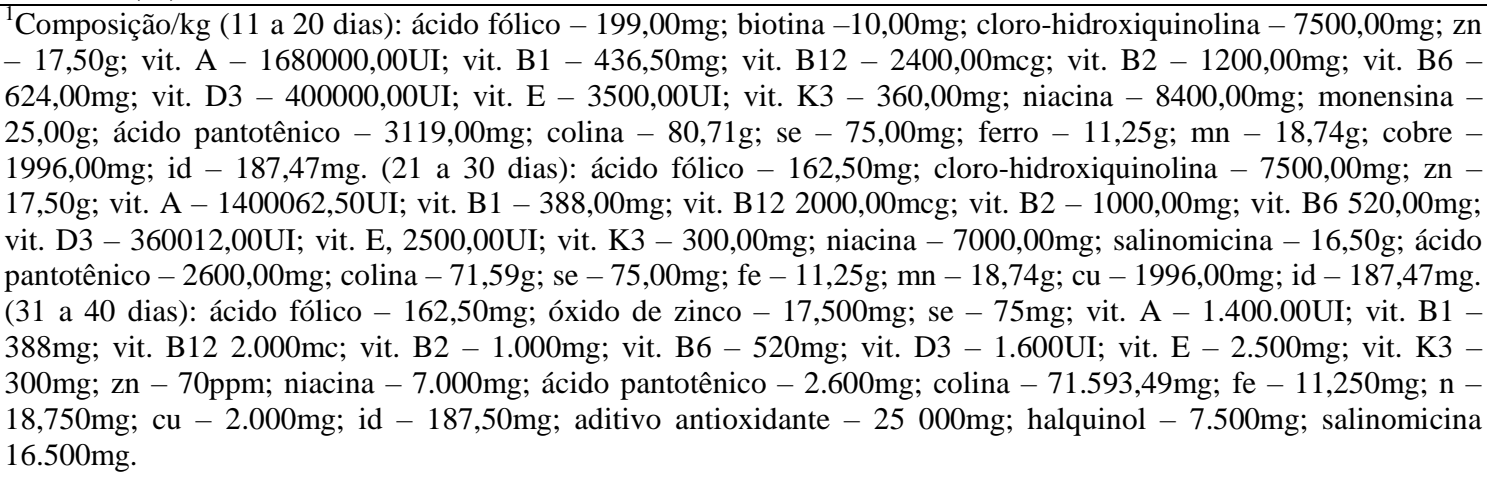 } \\
\hline
\end{tabular}


Os pintos foram alojados em um galpão convencional do primeiro ao $10^{\circ}$ dia de idade e, posteriormente, transferidos para gaiolas de estudos de metabolismo, onde foram iniciados os ensaios, respeitando-se a idade e o peso dos animais para cada fase. As aves não utilizadas no período experimental foram mantidas em galpão convencional, com bebedouro pendular, comedouro tubular e piso coberto com casca de arroz, arraçoados com dieta formulada para atender as exigências nutricionais de cada fase, segundo as recomendações de Rostagno et al. (2011), e foram manejadas conforme manual da linhagem.

No início de cada fase experimental, as aves foram pesadas individualmente e distribuídas em gaiolas de estudos de metabolismo, dispostas em baterias de três andares, onde foram mantidas até o final de cada fase. A ração e a água foram fornecidas à vontade. Foi utilizado o método de coleta total de excretas durante nove dias, em que cinco foram de adaptação experimental e quatro de coleta total, realizadas em intervalos de 12 horas. Determinaram-se o consumo de ração e o total de excretas produzidas. Após as coletas, as excretas foram acondicionadas em sacos plásticos, os quais foram identificados e mantidos em freezer. Ao final do experimento, as excretas foram homogeneizadas, amostradas (300g), secas em estufa de circulação forçada a $55^{\circ} \mathrm{C}$, por 72 horas, e moídas em moinho tipo Willey para análises posteriores. As análises laboratoriais das dietas e das excretas foram realizadas seguindo as metodologias propostas por Silva e Queiroz (2002).

Obtidos os resultados das análises laboratoriais, avaliou-se a energia metabolizável aparente (EMA), a energia metabolizável aparente corrigida pelo balanço de nitrogênio (EMAn) e os coeficientes de digestibilidade da matéria seca (MS), proteína bruta (PB) e energia bruta (EB), utilizando-se as equações propostas por Matterson et al. (1965).Com base nos valores de EMAn determinados para as dietas experimentais, foi possível calcular o valor de EMAn do milheto sobre a influência das enzimas CES e CEV:

$$
\begin{gathered}
\text { EMAn }(\text { milheto s } / \text { enzima })=E M A(\text { dieta } 1)+\frac{(E M A(\operatorname{dieta} 4)-E M A(\operatorname{dieta} 1)}{\% \text { de substituição do milheto }} \\
\text { EMAn }(\text { milheto } \mathrm{c} / \text { enzima CES })=E M A(\text { dieta } 2)+\frac{(E M A(\operatorname{dieta} 5)-E M A(\operatorname{dieta} 2)}{\% \text { de substituição do milheto }} \\
\text { EMAn }(\text { milheto } \mathrm{c} / \text { enzima CEV })=E M A(\text { dieta } 3)+\frac{(E M A(\operatorname{dieta} 6)-E M A(\text { dieta } 3)}{\% \text { de substituição do milheto }}
\end{gathered}
$$

Os dados foram submetidos à análise de variância pelo procedimento GLM do SAS. Os valores obtidos foram comparados pelo teste de Student-Newman-Keuls (SNK), considerando-se o nível de significância de $5 \%$.

\section{RESULTADOS E DISCUSSÃO}

No ensaio 1 (11 a 20 dias), verificou-se redução nos valores de EMA, EMAn do milheto com complexo enzimático $\mathrm{CEV}$ e aumento e redução do CDPB com a adição do CES e do CEV, respectivamente $(\mathrm{P}<0,05)$. Para CDMS e CDEB, não foi verificado efeito significativo $(\mathrm{P}>0,05)$ (Tab. 3).
No ensaio 2 (21 a 30 dias), houve efeito significativo com as adições enzimáticas $(\mathrm{P}<0,05)$, de maneira que os valores de EMA, EMAn, CDMS, CDPB e CDEB foram reduzidos (Tab. 3).

Foram observadas reduções na EMA e na EMAn do milheto no ensaio 3 (31 a 40 dias) com a adição dos complexos enzimáticos CES e CEV, no CDMS com o complexo CEV, e observou-se aumento no CDPB com o CEV $(\mathrm{P}<0,05)$, enquanto o CDEB foi semelhante $(\mathrm{P}>0,05)$ (Tab. 3). 
Tabela 3. Energia metabolizável aparente (EMA), energia metabolizável aparente corrigida para o nitrogênio (EMAn), coeficientes de digestibilidade da matéria seca (CDMS), da proteína bruta (CDPB) e da energia bruta (CDEB) na matéria natural do milheto para frangos de corte

\begin{tabular}{|c|c|c|c|c|c|}
\hline \multirow[t]{2}{*}{ Tratamentos } & \multicolumn{3}{|c|}{$(\mathrm{kcal} / \mathrm{kg}$ de MS $)$} & $\begin{array}{l}\text { CDPB } \\
(\%)\end{array}$ & CDEB \\
\hline & \multicolumn{5}{|c|}{ Ensaio $1-11$ a 20 dias } \\
\hline Milheto & $3456 a$ & $3321 \mathrm{a}$ & 75,87 & $50,07 \mathrm{~b}$ & 73,58 \\
\hline Milheto + CES & $3445 a$ & $3248 \mathrm{a}$ & 75,83 & $63,34 a$ & 74,69 \\
\hline Milheto + CEV & $2962 b$ & $2856 \mathrm{~b}$ & 74,64 & $43,56 \mathrm{c}$ & 73,21 \\
\hline Coeficiente de variação & 4,631 & 4,342 & 4,119 & 3,571 & 3,370 \\
\hline \multirow[t]{2}{*}{ Probabilidade } & 0,0006 & 0,0002 & ns & $<0,001$ & ns \\
\hline & \multicolumn{5}{|c|}{ Ensaio $2-21$ a 30 dias } \\
\hline Milheto & $3613 a$ & $3417 \mathrm{a}$ & $78,69 a$ & $65,79 a$ & $75,49 a$ \\
\hline Milheto + CES & $3417 b$ & $3203 b$ & $73,86 b$ & $54,68 \mathrm{~b}$ & $72,90 \mathrm{ab}$ \\
\hline Milheto + CEV & $3253 c$ & $3127 b$ & $73,63 b$ & $43,54 \mathrm{c}$ & $70,87 b$ \\
\hline Coeficiente de variação & 2,732 & 2,852 & 2,864 & 2,757 & 2,745 \\
\hline \multirow[t]{2}{*}{ Probabilidade } & 0,0002 & 0,0006 & 0,0027 & $<0,001$ & 0,0107 \\
\hline & \multicolumn{5}{|c|}{ Ensaio $3-31$ a 40 dias } \\
\hline Milheto & $3468 \mathrm{a}$ & $3383 a$ & $73,06 a$ & $42,23 b$ & 69,31 \\
\hline Milheto + CES & $3265 \mathrm{ab}$ & $3171 b$ & $71,64 a$ & $40,07 \mathrm{~b}$ & 68,58 \\
\hline Milheto + CEV & $3103 b$ & $2892 \mathrm{c}$ & $66,25 b$ & $51,85 \mathrm{a}$ & 68,46 \\
\hline Coeficiente de variação & 4,743 & 4,317 & 4,233 & 11,837 & 4,853 \\
\hline Probabilidade & 0,0055 & 0,0002 & 0,0088 & 0,0199 & $\mathrm{~ns}$ \\
\hline
\end{tabular}

Médias com letras diferentes na coluna diferem pelo teste de SNK (P<0,05); ns: não significativo.

$\mathrm{Na}$ fase de 11 a 20 dias, os valores de EMA com e sem a suplementação de CES foram semelhantes, porém esse complexo promoveu um incremento do CDPB do milheto. De acordo com Leite et al. (2012), as enzimas utilizadas no complexo podem influenciar a eficácia do produto, além de outros fatores, como a idade dos frangos, os ingredientes que compõem as rações, a forma e o momento da aplicação das enzimas, a exposição a altas temperaturas, a aplicação em quantidades precisas e a distribuição uniforme nas dietas. Considerando que os complexos continham mais de uma atividade enzimática, presume-se que os efeitos tenham sido influenciados pelo tipo de enzima, ao se observarem melhores resultados para o CES, que possuía maior variedade de enzimas na sua composição, como as enzimas fitases, proteases, xilanases, $\beta$-glucanases, celulases, amilases e pectinases, em relação ao $\mathrm{CEV}$, que continha apenas as enzimas proteases, celulases e amilases.

Além disso, o milheto possui em sua composição maiores quantidades de fibra e proteína do que o milho ((Rostagno et al., 2017), resultando em maior quantidade de substrato para atuação das enzimas celulase, xilanase, $\beta$-glucanase e pectinase, que atuam na degradação das fibras ou dos polissacarídeos não amiláceos presentes na dieta, reduzindo a viscosidade para que outras enzimas, como proteases, tenham sua efetividade e, como resposta, um incremento no CDPB.

Leite et al. (2011) observaram desvantagens da adição de enzimas sobre os coeficientes de digestibilidade de nutrientes do milheto com o complexo enzimático contendo as enzimas fitase, protease, $\beta$-glucanase, pentosanase, celulase, amilase e pectinase, em dietas elaboradas com milheto, no período de 10 a 14 dias. Estudos mostram a eficiência de utilização das enzimas em dietas elaboradas com outros ingredientes, como sorgo, milho e farelo de soja (Rodrigues $e t$ al., 2003; Rao et al., 2004; Barbosa et al., 2008; Leite et al., 2011).

O efeito negativo da adição enzimática (CES e $\mathrm{CEV}$ ) no segundo ensaio foi observado em todas as variáveis analisadas. Baurhoo et al. (2011) verificaram melhor resposta à adição enzimática em dietas à base de milho e farelo de soja do que em dietas à base de milheto para frangos de corte, pois geralmente o milho é fornecido na forma moída, o que aumenta a área de atuação das enzimas digestivas. Conforme Ribeiro et al. 
(2002) e Pereira (2008), a forma física da ração pode interferir na degradação do amido, sendo necessário o rompimento das camadas protetoras do endosperma para melhor atuação das enzimas digestivas, tanto endógenas como exógenas, pois a estrutura das partículas de uma dieta pode influenciar a digestibilidade dos nutrientes.

Fischer et al. (2002) avaliaram a inclusão de um complexo enzimático à base de protease, amilase e celulase, semelhante à composição do CEV utilizado neste estudo, em dietas à base de milho e farelo de soja, e verificaram que, na última semana (35 dias), o desempenho de frangos de corte alimentados com dietas contendo o complexo enzimático foi inferior, quando comparado ao desempenho dos animais que receberam dietas sem a inclusão de enzimas.

Nos resultados obtidos no ensaio 3 (31 a 40 dias), verificou-se que as suplementações enzimáticas não resultaram em melhorias das características avaliadas, exceto para o CDPB, que aumentou com a suplementação com o CEV. A secreção enzimática aumenta com a idade; com isso, espera-se melhor resposta na utilização da energia e dos nutrientes da dieta. Entretanto, segundo Noy e Sklan (1997) e Rao et al. (2004), é necessária uma adequação da secreção de enzimas no intestino para a degradação dos nutrientes, mesmo em dietas com milho e farelo de soja, pois vários autores não encontraram respostas positivas no crescimento de frangos de corte com a adição enzimática à base desses ingredientes.

A melhor resposta para o CDPB com a utilização do CEV no período de 31 a 40 dias de idade pode estar associada à idade e ao tipo de ingrediente. Sakomura et al. (2004) verificaram que ocorre um aumento da produção de enzimas digestivas em função da idade do frango, quando testaram diferentes tipos de soja. A maturidade do trato digestório e a utilização do CEV foram suficientes para elevar o coeficiente de digestibilidade da proteína, mesmo com a utilização de um complexo com menor variedade de enzimas em sua composição.

Dietas elaboradas com milheto e farelo de soja podem ser melhoradas com suplementação enzimática específica, principalmente aquelas que degradem a fração indigestível contida no grão de milheto. No entanto, são necessários novos estudos para o desenvolvimento de enzimas que utilizem este ingrediente como substrato. Strada et al. (2005) encontraram resultados satisfatórios na eficiência de utilização da energia metabolizável e dos aminoácidos com a adição de um complexo multienzimático semelhante ao utilizado neste estudo em rações à base de farelo de soja e milho para frangos de corte de 22 a 42 dias.

\section{CONCLUSÃO}

A inclusão dos complexos enzimáticos CES (fitase, protease, xilanase, $\beta$-glucanase, celulase, amilase e pectinase) e CEV (protease, celulase e amilase) não favoreceu a utilização da energia do milheto, no entanto melhorou o coeficiente de digestibilidade da proteína do milheto nos períodos de 11 a 20 e de 31 a 40 dias de idade.

\section{REFERÊNCIAS}

BARBOSA, N.A.A.; SAKOMURA, N.K., FERNANDES, J.B.K.; DOURADO, L.R.B. Enzimas exógenas no desempenho e na digestibilidade ileal de nutrientes em frangos de corte. Pesqui. Agropecu. Bras., v.43, n.6, 755762, 2008.

BASTOS, A.O.; MOREIRA, I.; FURLAN, A.C. et al. Composição química, digestibilidade dos nutrientes e da energia de diferentes milhetos (Pennisetum glaucum (L.) R. Brown) em suínos. Rev. Bras. Zootec., v.34, p.2, 520-528, 2005.

BAURHOO, N.; BAURHOO, B.; ZHAO, X. Effects of exogenous enzymes in corn-based and Canadian pearl millet-based diets with reduced soybean meal on growth performance, intestinal nutrient digestibility villus development, and selected microbial populations in broiler chickens. J. Anim. Sci., v.89, p.4100-4108, 2011.

BRITO, M.S.; OLIVEIRA, C.F.S.; SILVA, T.R.G. et al. Composição Química, Digestibilidade dos Nutrientes e da Energia de Diferentes Milhetos (Pennisetum glaucum (L.) R. Brown) em Suínos. Acta Veterinaria Brasilica, v.2, n.4, p. 111-117, 2008.

FISCHER, G.; MAIER, J.C.; RUTZ, F.; BERMUDEZ, V.L. Desempenho de frangos de corte alimentados com dietas à base de milho e farelo de soja, com ou sem adição de enzimas. Rev. Bras. Zootec., v.31, p.402-410, 2002. 
GOMES, P.C.; RODRIGUES, M.P.; ALBINO, L.F.T. et al. Determinação da composição química e energética do milheto e sua utilização em rações para frangos de corte de 1 a 21 dias de idade. Rev. Bras. Zootec., v.37, p.1617-1621, 2008.

LEITE, P.R.S.C.; LEANDRO, N.S.M.; STRINGHINI, J.H. et al. Desempenho de frangos de corte e digestibilidade de rações com sorgo ou milheto e complexo enzimático. Pesqui. Agropecu. Bras., v.46, p.280-286, 2011.

LEITE, P.R.S.C.; LEANDRO, N.S.M.; STRINGHINI, J.H. et al. Microbiota intestinal e desempenho de frangos alimentados com rações elaboradas com sorgo ou milheto e complexo enzimático. Arq. Bras. Med. Vet. Zootec., v.64, p.1673-1681, 2012.

MATTERSON, L.D.; POTTER, L.M.; STUTZ, N.W. et al. The metabolizable energy of feed ingredients for chickens. Res. Rep., v.7, p.311,1965 .

NOY, Y.; SKLAN, D. Posthatch development in poultry. J. Appl. Poult. Res., v.6, p.344-354, 1997.

OLIVEIRA, M.C.; CANCHERINI, L.C.; GRAVENA, R.A. et al. Utilização de nutrientes de dietas contendo mananoligossacarídeo e/ou complexo enzimático para frangos de corte. Rev. Bras. Zootec., v.36, p.825-831, 2007.

PEREIRA, P. W. Z. Avaliação de complexo enzimático e betaína natural nas rações de frangos de corte. 2008. 64f. Dissertação (Mestrado em Agronomia) - Universidade de São Paulo, São Paulo.

RAO, S.V.R.; RAJU, M.V.L.N.; REDDY, M.R.; PANDA, A.K. Replacement of yellow maize with pearl millet (Pennisetum typhoides), Foxtail millet (Setaria italica) or Finger millet (Eleusine coracana) in broiler chicken diets containing supplemental enzymes. Asian Aust. J. Anim. Sci., v.17, p.836-842, 2004.
RIBEIRO A.M.L.; MAGRO, N.; PENZ JR, A.M. Granulometria do milho em rações de crescimento de frangos de corte e seu efeito no desempenho e metabolismo. Rev. Bras. Cienc. Avic., v.4, p.47-53, 2002.

RODRIGUES, P.B.; ROSTAGNO H.S.; ALBINO, L.F.T. et al. Desempenho de frangos de corte, digestibilidade de nutrientes e valores energéticos de rações formuladas com vários milhos, suplementadas com enzimas. Rev. Bras. Zootec., v.32, p.171-182, 2003.

ROSTAGNO, H.S.; ALBINO, L.F.T.; DONZELE, J.L. et al. Tabelas brasileiras para aves e suínos: composição de alimentos e exigências nutricionais. 3.ed. Viçosa, MG: Universidade Federal de Viçosa, 2011. 252p.

SAKOMURA, N.K.; BIANCH, M.D.; PIZAURO JR, J.M. et al. Efeito da idade dos frangos de corte sobre a atividade enzimática e digestibilidade dos nutrientes do farelo de soja e da soja integral. Rev. Bras. Zootec., v.33, p.924935, 2004.

SAKOMURA, N.K; ROSTAGNO, H.S. Métodos de pesquisa em nutrição de monogástricos. Jaboticabal: Funep, 2007. 283p.

SILVA, D.J; QUEIROZ, A.C. Análise de alimentos: métodos químicos e biológicos. 3.ed. Viçosa: UFV, 2002. 235p.

STRADA, E.S.O.; ABREU, R.D.; OLIVEIRA, G.J.C. et al. Uso de Enzimas na alimentação de frangos de corte. Rev. Bras. Zootec., v.34, p.2369-2375, 2005. 